\title{
Effect of 8 weeks Aerobic Training and Nigella Supplement on Insulin Resistance, Lipid Profile and Plasma Level of HbA1c in Type 2 Diabetic Rats
}

\author{
Solmaz Babaei Bonab ${ }^{*^{*} \text { (D) }}$, Asghar Tofighi ${ }^{2}$ iD
}

1.Dept. of Sport Sciences, Faculty of Humanities, University of Maragheh, Maragheh, iran

2. Dept. of Physical Education and Sport Sciences, Urmia University, Urmia, Iran

\begin{tabular}{|c|c|}
\hline Article Info & ABSTRACT \\
\hline doi $10.30699 / j a m b s .27 .120 .20$ & \multirow{2}{*}{$\begin{array}{l}\text { Background \& Objective: Metabolic syndrome is defined as a cluster of metabolic } \\
\text { disorders, which may lead to type II diabetes and cardiovascular diseases. The aim of } \\
\text { this study was to investigate the effect of } 8 \text { weeks of aerobic training and Nigella } \\
\text { sativa supplements on insulin resistance, lipid profiles, and plasma levels of HbA1c } \\
\text { in Type } 2 \text { diabetic rats. }\end{array}$} \\
\hline $\begin{array}{l}\text { Received: 2018/08/08; } \\
\text { Accepted: 2018/12/15; } \\
\text { Published Online: 01 Jan 2019; }\end{array}$ & \\
\hline \multirow{2}{*}{ 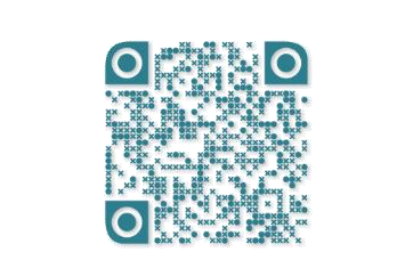 } & $\begin{array}{l}\text { Materials \& Methods: } 35 \text { male Wistar rats were divided into five groups. Diabetes } \\
\text { was induced by intraperitoneal injection of streptozotocin. The training program } \\
\text { included } 8 \text { weeks of aerobic training on a treadmill. The supplement group consumed } \\
\text { N. Sativa supplement at the end of each training session at the dose of } 400 \mathrm{mg} / \mathrm{kg} / \mathrm{day} \text {. } \\
\text { After } 8 \text { weeks of aerobic training and N.Sativa consumption, the plasma levels of } \\
\text { HbA1C, insulin resistance and lipid profiles were measured. }\end{array}$ \\
\hline & $\begin{array}{l}\text { Results: The results showed that blood glucose level in all three groups was } \\
\text { significantly lower than the baseline }(P=0.0001) \text {. Cholesterol, triglyceride and LDL } \\
\text { showed the most significant decrease in aerobic and combination training groups } \\
(P=0.0001) \text {. In HDL index, aerobic and combined exercise groups showed a significant }\end{array}$ \\
\hline \multirow{3}{*}{$\begin{array}{l}\text { Corresponding Information: } \\
\text { Solmaz Babaei Bonab, Dept. of Sport } \\
\text { Sciences,Faculty of Human Sciences, } \\
\text { University of Maragheh, Maragheh, Iran } \\
\text { Email: s.babaei@ maragheh.ac.ir }\end{array}$} & group showed a significant decrease compared to the other groups $(P=0.0001)$. \\
\hline & $\begin{array}{l}\text { Conclusion: The results shows that exercise along with N. Sativa supplement is more } \\
\text { effective than N. sativa supplement or exercise alone in the status of rats with type } 2 \\
\text { diabetes. This kind of combination therapy may also be applicable to diabetic patients. }\end{array}$ \\
\hline & Keywords: Diabetes, Aerobic Training, Nigella, Insulin resistance \\
\hline (c) (1) @ & $\begin{array}{l}\text { access article distributed under the terms of the Creative Commons Attribution-noncommercial } 4.0 \text { International License which permits } \\
\text { noncommercial usages with proper citation. }\end{array}$ \\
\hline
\end{tabular}

\section{Introduction}

Diabetes mellitus is a deadly metabolic disorder characterized by a chronic increase in blood sugar and carbohydrate metabolism, fat, and protein (1). The disease is caused by an insufficiency in insulin secretion, its function, or both, which causes a disturbance in the metabolism of the body's sugar levels, resulting in higher than normal sugar levels (1). Type 2 diabetes, which accounts for more than $90 \%$ of diabetes cases, has many long-term complications including vascular complications, which in addition to lowering the quality of life and imposing medical costs, it also bears the risk of mortality 2 to 4 times more than individuals who don't have this disease (2). Diabetes is an epidemic, and according to the World Health Organization (WHO), it will affect 380 million people by 2025 (3). Also, the World Health Organization estimates that chronic diseases, such as diabetes, will be the leading cause of mortality in the world in the next few years (1). Although chronic diseases are not life-threatening, they are a major threat to health, one's economic status, and the quality of life of individuals, families, and communities (4). Type 2 diabetes is a chronic disease that affects a person in terms of general health and social welfare in different ways (5). This global epidemic is due more to obesity and immobility (5). Increasing adipose tissue causes chronic inflammatory conditions that play an important role in the progression of insulin resistance and type 2 diabetes (6). An abnormal increase in low density lipoprotein levels has been reported in those who are resistant to insulin, which results in increased triglyceride levels and abnormal levels of high density lipoprotein levels (7). Insulin, defined as a reduction in the response of peripheral tissues to insulin function, is a major contributor to the development of type 2 diabetes and its long-term complications. In addition, insulin resistance destroys glucose uptake by insulin-sensitive tissue and increases glucose production of the liver, serum glucose, and $\mathrm{HbA} 1 \mathrm{c}$. Exercise plays an important role in the prevention and control of type 2 diabetes (8). According to the current guidelines, patients with type 2 diabetes should have at least 150 minutes of aerobic exercise per week with moderate intensity and resistance training 3 
times per week (9). Recent studies have shown that organized exercise, including aerobic and resistance training, reduce $\mathrm{HbA} 1 \mathrm{C}$ levels to -0.6 percent (9). The researchers showed that a combination of aerobic and resistance exercises reduced the HbA1C by $-0.97 \%$ in type 2 diabetic patients (10). The reduction of $\mathrm{HbAlc}$ in type 2 diabetic patients is associated with improved insulin resistance and reduction of cardiovascular problems and capillary problems (10). Research results have shown that recurring muscle contractions in the absence of insulin in type 2 diabetic patients who have insulin sensitivity, facilitate entrance, ingestion andconsumption of glucose by the muscle cells, Exercise also increases the level of carrier protein (GLUT4), which reduces insulin resistance (1).

The relationship between the increase in physical activity levels and the reduction in incidence of long-term complications of diabetes suggests that physical activity plays a protective role, recently, there has been an increase of interest towards the usage of supplements and herbal medication which has been derived from medicinal plants; these plants can have major preventive effects on patients. Among these plants, Nigella is one that has a rich medical and religious history. This plant is native to South America, North Africa and Asia. The seeds of Nigella are known as black celery, with the scientific name Nigella sativa $L$ of the Ranoculaceae family (11).

Nigella is widely used in the treatment of asthma, headache, obesity, cardiovascular disease, hypertension, and gastrointestinal problems (12). Four types of alkaloids with the names Nijalamin B (2), B (1), A (2), A (1) were supplemented from Nigella seeds. Tamioquinone, dimitonquinone and dihydroquinone and thymol are the main effective matters in Nigella seed's aqueous supplement. The oil content is $30 \%$ by weight and Pcymen is the main compound. The effects of antioxidant, anti-inflammatory, immunosuppressive and antihistaminic properties of oil and Supplements of Nigella seeds have caused several pharmacological effects, such as decreased sugar, lipids, and hypertension, bile and uric acid excretion, protection of liver, kidney and Cardiovascular system. Moreover, anti-microbial and anti-parasites effects of this plant has also been reported (13). Additionally, the use of Nigella has inotropic and hypertrophic effects on the heart. Nigella also has a profound effect on diabetic patients, such that it affects beta cells and increases insulinotropic levels of serum insulin and decreases blood glucose levels (14). Aerobic activity is also known to be a non-pharmacological and effective way to manage and control diabetes by reducing blood glucose and hemoglobin (HbAlc) in diabetic patients (14). Many studies have been performed on the effect of exercise on blood and hormonal markers of diabetes, but a study has yet to be found on the effect of aerobic training and the usage of Nigella supplements on biochemical markers in diabetic rats. Therefore, the purpose of this study was to investigate the effect of 8 weeks of aerobic training and nigella supplement consumption on insulin resistance, lipid profiles, and plasma levels of HbAlc in type 2 diabetic rats.

\section{Materials and Methods}

\section{Reagents and chemicals}

HbA1C measurements were performed by ion exchange chromatography with Biosystems Company in Barcelona, Spain; intra-Assay CV: 5.4\%, inter-Assay CV: $7.3 \%$ ). The index of insulin resistance was calculated using the HOMA-IR homeostasis model and evaluated according to the following formula:

HOMA-IR = fasting glucose [mmol/l] $x$ fastin insulin $[\mu U / m l] / 22.5$ (15).

Measurement of lipid profiles were automatically performed by using an enzymatic method and Pars Company test kits with a sensitivity of $1 \mathrm{mg} / \mathrm{dl}$ in Alcyon 3000 (Abbotte-USA).

The plasma glucose level was measured by an enzymatic colorimetric based on the glucose oxidase method with an autoanalysis device(Hitachi 902, Behringer Menheim, Germany) and a special kit from Pars Company, by $1 \mathrm{mg} / \mathrm{dl}$ sensitively.

\section{Animals}

Male Wistar rats with age (6 to 8 weeks) and weight $(214.69 \pm 3.63$ grams $)$ were collected from the West Azarbaijan Animal Hospital (Urmia). The animals tested during the research stages were maintained in Shafaa polycarbonate cages in standard environmental conditions (ambient temperature $21 \pm 2{ }^{\circ} \mathrm{C}$, humidity $45 \pm 55 \%$, dark and light cycle of 12:12 hours), without an access limitation to water and food.

\section{Induction of type 2 diabetes}

After a week of the rats adaptation to the environment, an intraperitoneal injection of Streptozotocin $(50 \mathrm{mg} / \mathrm{kg}$ body weight) with normal saline carrier was used to induce diabetes. With this method, within 48 hours of the injection, the rats' diabetic levels were induced which was confirmed by a small lacrimal injury in the animal's tail, a drop of blood transmitted on the glucometer tape $300 \mathrm{mg}$ / dl was considered as an index of diabetic glucose and high blood glucose (16) with the Research Ethics Committee of Sport Sciences Research code IR.SSRI.REC.1397.251.

\section{Nigella Supplement}

Nigella supplements were prepared from Iran's Kurdistan region by milled powder and supplemented with $250 \mathrm{ml}$ of $\mathrm{N}$-hexane solution made by Merk Company for 2 hours. Then, the supplement was passed through filter paper and concentrated at vacuum at $50^{\circ} \mathrm{C}$ and the oil-based supplement was retained in a yellow color. Nigella supplements were fed to rats based on body weights, and at the end of each training session was gavaged with an effective dose of $400 \mathrm{mg} / \mathrm{kg} /$ day (17). In order to equalize the conditions (gavage shock) to other groups in equal volumes, water was gavaged. The weight of the rats were measured once a week and recorded. 


\section{Training program}

The intensity of the rat's aerobic activity was controlled using their running bar speed. A rat's running speed of 20$25 \mathrm{~m} / \mathrm{min}$ was considered as average aerobic activity (18). The training program included aerobic training on the treadmill for 8 consecutive weeks and 5 days a week. Initially, the rats were trained for one minute at speeds of 5 to $10 \mathrm{~m} / \mathrm{min}$ for 10 minutes, with a zero-tilt slope on the treadmill, which was a manufacturing of Azma Technological Company, with automatic planning (familiarization stage). After a week of treadmill compatibility, the intensity of the activity in the first two weeks at $10 \mathrm{~m} / \mathrm{min}$ speed, the gradient of $5^{\circ}$ for 15 minutes, followed by gradually increasing intensity and duration of the activity every two weeks. In the last two weeks, the intensity of the activity was increased to $25 \mathrm{~m}$ /min, the duration of the activity was 30 minutes, and the treadmill stead on 5 degrees until the end of the training period. It should be noted that of the total 30 minutes, the beginning of each training session was considered as warm up for 5 minutes (speed of $10 \mathrm{~m} / \mathrm{min}$ and zero slope) and 5 minutes were considered as cool down at the end of each session, where the treadmill speed decreased steadily to reach the initial speed. During these 8 weeks, control rats walked on a treadmill one session a week for 5 minutes at a speed of $10 \mathrm{~m} / \mathrm{min}$ and a zero-degree slope, in order to gain familiarization with the treadmill. This protocol has been designed increasingly and in accordance with the scientific principles of the ASCM Association (19).

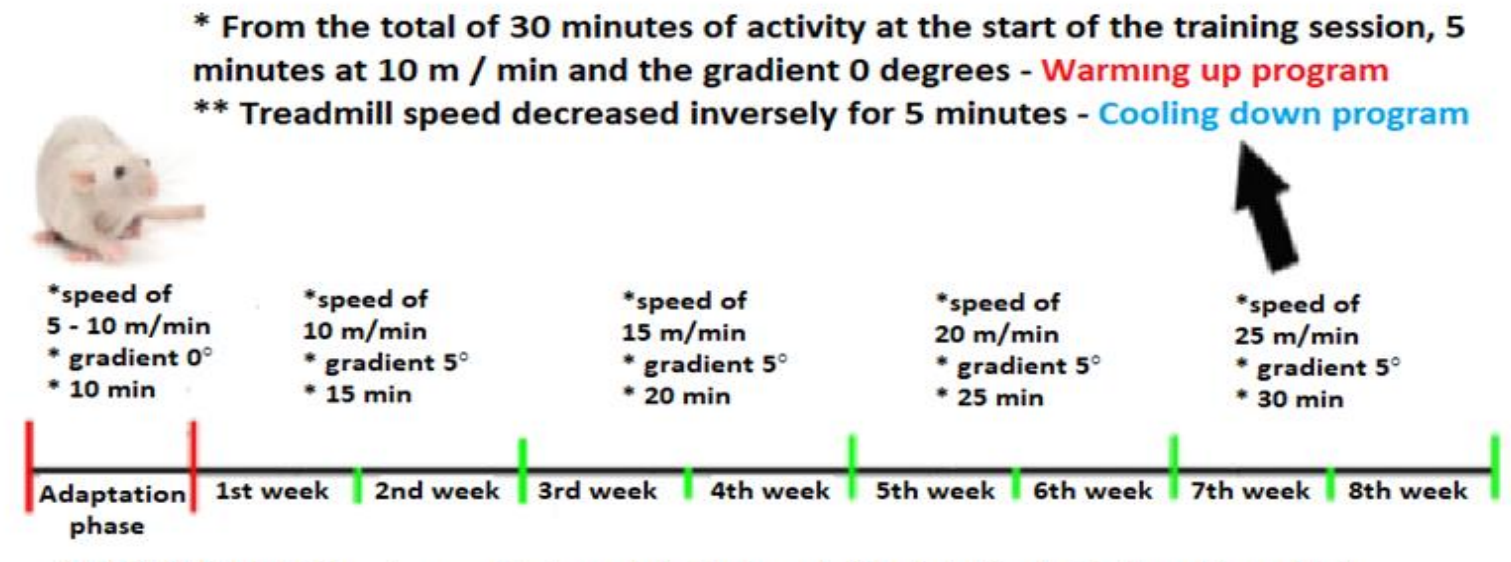

1. Control group ( 8 weeks, one session in a week, for $5 \mathrm{~min}$, speed of $10 \mathrm{~m} / \mathrm{min}, 0^{\circ}$ gradient and in walking condition)

\section{The diabetic group}

3. Diabetic group with aerobic training

\section{Diabetic group receiving black grain extract}

5. Diabetic group receiving black grain extract with aerobic training

Figure 1. Training protocol

\section{Blood sampling}

This research was registered as number 1199241. 48 hours after the last training session and 12 hours after fasting, the rats were anesthetized with Ketamine (80 mg / $\mathrm{kg}$ body weight). Then, the skin of the abdomen and chest was cut through the opening of the abdominal cavity and about $10 \mathrm{ml}$ of blood was taken directly from the rats' heart by syringe and transferred to test tubes containing EDTA. After, the collected samples were rapidly centrifuged at a speed of $3000 \mathrm{rpm}$ for 10 minutes (the model of the device was UNIVERSAL $320 \mathrm{R}$, Hettich made in Germany). The obtained plasma was stored at $80^{\circ} \mathrm{C}$ until the conduction time of the experiments.

The present study was a quasi-experimental, field and laboratory method, in which 35 male Wistar rats were divided into 5 groups with 7 subjects in each group. The first group (control) participated only in a one-day training program; the second group (diabetic) was diabetic with intraperitoneal injections of Streptozotocin (50 mg / kg); the third group (diabetic + aerobic training) consisted of diabetic rats, which participated in 8 weeks aerobic training. The forth group (diabetic + Nigella supplement) were diabetic rats which received Nigella supplements by gavage (400 mg / kg / day). The fifth group (diabetic + aerobic exercise + Nigella supplement) were diabetics who in addition to receiving Nigella supplements, participated in the aerobic training program. The summary of the animal groupings was as follows:

\section{Control group}

2. Diabetic group

3. Diabetic group with aerobic training

4. Diabetic group receiving Nigella supplements

5. Diabetic group receiving Nigella supplements with aerobic training 


\section{Statistical analysis}

The data was analyzed using SPSS software version 23. After normalizing the variables, one-way ANOVA was used and the the mean of the variables in the five groups were statistically analyzed. Hoek's follow-up test was used for statistical differences between the groups. The results of this study were reported as mean \pm standard deviation, and the difference was statistically considered with a significance level of $5 \%$.

\section{Results}

Weight and blood glucose of rats (fasting blood glucose levels in diabetic groups were at baseline after STZ injection), as shown in Table 1 at the start of the study and after treatment. Weight loss and fasting blood glucose were observed in all groups. In the weight index except for the control group + diabetic group $(P=0.53)$ and diabetic + training group with diabetic group + Nigella supplement + training $(P=0.23)$, the rest of the group had a significance difference with each other $(P<0.005)$. Also, in the fasting blood glucose index, except diabetic group $(P=1)$ and diabetic + training group with diabetic + Nigella supplement $(P=0.91)$ and diabetic + Nigella supplement + training $(P=0.11)$, there was a significance difference in fasting blood glucose with each other $(P<0.005)$.

Table 1. Comparison of weight and fasting blood glucose in five groups of rats (mean \pm SD) in each group of 7 rats

\begin{tabular}{|c|c|c|c|c|}
\hline \multirow[b]{2}{*}{ Group } & \multicolumn{2}{|c|}{ Weight (kg) } & \multicolumn{2}{|c|}{ Fast blood glocuse } \\
\hline & Beginning of study & After 8 weeks & Beginning of study & After 8 weeks \\
\hline control & $217.03 \pm 1.49$ & $219.9^{\text {cde }} \pm 1.88$ & $102.46 \pm 3.95$ & $96.91^{\text {cde }} \pm 2.32$ \\
\hline Diabetic & $216.05 \pm 1.78$ & $224.17^{\text {cde }} \pm 1.47$ & $373.57 \pm 5.96$ & $374.42^{\text {cde }} \pm 5.12$ \\
\hline Diabetic+Training & $215.36 \pm 1.5$ & $187.98^{\mathrm{abd}} \pm 2.69$ & $363 \pm 34.52$ & $284.95^{\mathrm{ab}} \pm 3.03$ \\
\hline Diabetic+Supplement & $210.62 \pm 6.01$ & $\begin{array}{c}198.63^{\text {abde }} \pm 11 \\
31\end{array}$ & $325.6 \pm 102.34$ & $302.94^{\mathrm{abe}} \pm 36.08$ \\
\hline Diabetic+Supplement+Training & $214.42 \pm 1.53$ & $180.38^{\mathrm{abd}} \pm 2.16$ & $387.3 \pm 3.85$ & $275.97^{\mathrm{abd}} \pm 3.43$ \\
\hline
\end{tabular}

${ }^{*} P<0.005$ a compared with the control group, $\mathrm{P}<0.005 \mathrm{~b}$ compared with the diabetic group, $\mathrm{P}<0.005 \mathrm{c}$ compared with the diabetic + training group,

$* * P<0.005 \mathrm{~d}$ compared with the diabetic Supplement group, $\mathrm{P}<0.005 \mathrm{e}$ compared with the diabetic + Supplement+exercise group

According to Table 2, it is observed that the total cholesterol and triglyceride index in the diabetic group and the diabetic+Nigella supplement group, in the LDL index of the diabetic group and the control group, as well as in the HDL index of the diabetic group+training and diabetic+supplement+aerobic training group had more quantities comparing to diabetic group. In the total cholesterol index, except for the control group with diabetic + supplement $(P=0.99)$ and diabetic + training group $(P=0.21)$, diabetic + training group with diabetic + supplement + training group $(P=0.36)$, and the rest of the groups had a significant difference $(P<0.005)$. In the triglyceride index, except for the control group, diabetic + Supplement $(P=0.98)$ and diabetic + training group $(P=$
0.05), diabetic + training group with diabetic + supplement + training group $(P=0.1)$, and there was a significant difference $(P<0.005)$. In the LDL index, apart from the control group with diabetic + supplement group $(P=0.26)$ and diabetic + Supplement group with diabetic + training group $(P=0.95)$, the other groups had a significant difference $(P<0.005)$. In the HDL index, apart from diabetic + supplement group $(P=1)$ and diabetic + training group $(P=0.83)$, diabetic + supplement and diabetic + training group $(P=0.64)$ and diabetic + training group with diabetic + supplement + training group $(P=$ $0.08)$, the rest of the groups had a significance difference $(P<0.005)$.

Table 2. Comparison of lipid profiles in five groups of rats (mean \pm SD) in each group of 7 rats

\begin{tabular}{|c|c|c|c|c|}
\hline Variables & $\begin{array}{c}\text { Total Cholesterol } \\
\text { (mg/dl) }\end{array}$ & $\begin{array}{l}\text { Triglyceride } \\
\text { (mg/dl) }\end{array}$ & $\begin{array}{l}\text { LDL } \\
\text { (mg/dl) }\end{array}$ & $\begin{array}{l}\text { HDL } \\
\text { (mg/dl) }\end{array}$ \\
\hline Control & $85.42^{\mathrm{be}} \pm 4.26$ & $84.75^{\text {be }} \pm 4.83$ & $31.63^{\mathrm{bce}} \pm 5.56$ & $37.84^{\mathrm{ae}} \pm 3.95$ \\
\hline Diabetic & $100.09^{\text {bcde }} \pm 8.02$ & $98.92^{\text {acde }} \pm 5.61$ & $46.29^{\text {acde }} \pm 4.18$ & $30.11^{\text {acde }} \pm 4.62$ \\
\hline Diabetic+Training & $78.74^{\mathrm{bd}} \pm 1.89$ & $76.91^{\mathrm{bd}} \pm 3.66$ & $25.42^{\text {abe }} \pm 1.99$ & $40.84^{\mathrm{b}} \pm 5.28$ \\
\hline Diabetic+Supplement & $87.52^{\text {bce }} \pm 7.19$ & $87.24^{\mathrm{bce}} \pm 7.11$ & $27.45^{\text {be }} \pm 2.22$ & $37.18^{\mathrm{be}} \pm 3.79$ \\
\hline Diabetic+Supplement+Training & $72.87^{\mathrm{abd}} \pm 1.74$ & $69.7^{\mathrm{abd}} \pm 2.26$ & $14^{\mathrm{abcd}} \pm 1.98$ & $46.9^{\mathrm{abd}} \pm 2.22$ \\
\hline
\end{tabular}

$* P<0.005$ a compared with the control group, $P<0.005 \mathrm{~b}$ compared with the diabetic group, $P<0.005 \mathrm{c}$ compared with the diabetic + training group,

$* * P<0.005 \mathrm{~d}$ compared with the diabetic Supplement group, $P<0.005$ e compared with the diabetic+Supplement+exercise group

According to Table 3, the hemoglobin A1C index was high in the control and diabetic groups. It was also high in the index of insulin resistance in the diabetic group. Insulin levels in the control group and the 
diabetic+supplement+aerobic training group, as well as apelin index in the diabetic+supplement+aerobic training group were higher than the other groups. In the Hemoglobin A1C index, except for the diabetic group $(P$ $=0.37)$, the other groups had a significant difference $(P$ $<0.005)$. In the diabetic group with diabetic+supplement group $(P=0.11)$, diabetic+supplement group with diabetic+training group $(P=0.84)$, diabetic+training group with diabetic+supplement+ training group $(P=$ $0.57)$, there was a significant difference between the other groups $(P<0.005)$. In the insulin resistance index, except for the diabetic+supplement group with diabetic+training group $(P=0.11)$, the remaining groups had a significant difference $(P<0.005)$.

Table 3. Comparison of hemoglobin A1C, insulin and insulin resistance index in four groups of rats (Mean \pm SD) in each group of 7 rats

\begin{tabular}{|c|c|c|c|}
\hline Group & Variables & $\begin{array}{c}\text { Hemoglobin A1C } \\
(\%)\end{array}$ & $\begin{array}{l}\text { HOMA-IR index } \\
(\%)\end{array}$ \\
\hline & Control & $8.66^{\text {cde }_{ \pm} \pm 0.28}$ & $1.84^{\text {bcde }} \pm 0.06$ \\
\hline & Diabetic & $8.81^{\text {cde }_{ \pm}} \pm 0.03$ & $7.57^{\text {acde }} \pm 0.13$ \\
\hline & Diabetic+Training & $7.35^{\text {abde }} \pm 0.02$ & $5.72^{\mathrm{abe}} \pm 0.17$ \\
\hline & Diabetic+Supplement & $7.63^{\text {abce }} \pm 0.05$ & $5.55^{\mathrm{abe}} \pm 0.14$ \\
\hline & Diabetic+Supplement+Training & $6.26^{\mathrm{abcd}} \pm 0.3$ & $5.18^{\mathrm{abcd}} \pm 0.02$ \\
\hline
\end{tabular}

$* P<0.005$ a compared with the control group, $P<0.005 \mathrm{~b}$ compared with the diabetic group, $\mathrm{P}<0.005 \mathrm{c}$ compared with the diabetic+training group,

$* * P<0.005 \mathrm{~d}$ compared with the diabetic Supplement group, $P<0.005$ e compared with the diabetic+Supplement+exercise

Table 4. ANOVA result for Fast blood glucose, CHOL, TG, LDL, HDL

\begin{tabular}{|c|c|c|c|c|c|c|}
\hline & & Sum of Squares & df & Mean Square & $\mathbf{F}$ & Sig \\
\hline \multirow{7}{*}{ Between Groups } & Fast blood glucose & 64895.58 & 4 & 16223.89 & $29.72 *$ & 0.0001 \\
\hline & CHOL & 2944.55 & 4 & 736.13 & $26.09 *$ & 0.0001 \\
\hline & TG & 3411.49 & 4 & 852.87 & $34.37 *$ & 0.0001 \\
\hline & LDL & 3822.28 & 4 & 955.57 & $77.91 *$ & 0.0001 \\
\hline & HDL & 1039.57 & 4 & 259.89 & $15.42 *$ & 0.0001 \\
\hline & Hemoglobin A1C & 30.35 & 4 & 7.58 & $446.39^{*}$ & 0.0001 \\
\hline & HOMA-IR index & 120.95 & 4 & 30.23 & $1963.68 *$ & 0.0001 \\
\hline \multirow{7}{*}{ Within Groups } & Fast blood glucose & 16376.26 & 30 & 545.87 & & \\
\hline & CHOL & 846.225 & 30 & 28.20 & & \\
\hline & TG & 744.37 & 30 & 24.81 & & \\
\hline & LDL & 367.84 & 30 & 12.26 & & \\
\hline & HDL & 505.55 & 30 & 16.85 & & \\
\hline & Hemoglobin A1C & 0.51 & 30 & 0.01 & & \\
\hline & HOMA-IR index & 0.46 & 30 & 0.01 & & \\
\hline \multirow{7}{*}{ Total } & Fast blood glucose & 81271.85 & 34 & & & \\
\hline & CHOL & 3790.77 & 34 & & & \\
\hline & TG & 4155.87 & 34 & & & \\
\hline & LDL & 4190.22 & 34 & & & \\
\hline & HDL & 1545.12 & 34 & & & \\
\hline & Hemoglobin A1C & 30.86 & 34 & & & \\
\hline & HOMA-IR index & 121.41 & 34 & & & \\
\hline
\end{tabular}

\footnotetext{
* The mean difference is significant at the 0.05 level.
} 


\begin{tabular}{|c|c|c|c|c|c|}
\hline & Group & Group & Mean Difference & Std. Error & Sig. \\
\hline \multirow{10}{*}{ Fast blood glucose } & \multirow{4}{*}{ Control } & Diabetic & -6.41 & 12.48 & 1 \\
\hline & & Diabetic+Training & $72.48^{*}$ & 12.48 & 0.0001 \\
\hline & & Diabetic+Supplement & $57.54^{*}$ & 12.48 & 0.001 \\
\hline & & Diabetic+Supplement+Training & $105.77 *$ & 12.48 & 0.0001 \\
\hline & \multirow{3}{*}{ Diabetic } & Diabetic+Training & $78.90 *$ & 12.48 & 0.0001 \\
\hline & & Diabetic+Supplement & $63.95^{*}$ & 12.48 & 0.0001 \\
\hline & & Diabetic+Supplement+Training & $112.18 *$ & 12.48 & 0.0001 \\
\hline & \multirow{2}{*}{ Diabetic+Training } & Diabetic+Supplement & -14.94 & 12.48 & 0.91 \\
\hline & & Diabetic+Supplement+Training & 33.28 & 12.48 & 0.11 \\
\hline & Diabetic+Supplement & Diabetic+Supplement+Training & $112.18 *$ & 12.48 & 0.0001 \\
\hline \multirow{10}{*}{$\mathrm{CHOL}$} & \multirow{4}{*}{ Control } & Diabetic & $-14.67 *$ & 2.83 & 0.0001 \\
\hline & & Diabetic+Training & 6.68 & 2.83 & 0.21 \\
\hline & & Diabetic+Supplement & -2.09 & 2.83 & 0.99 \\
\hline & & Diabetic+Supplement+Training & $12.55^{*}$ & 2.83 & 0.01 \\
\hline & \multirow{3}{*}{ Diabetic } & Diabetic+Training & $21.35^{*}$ & 2.83 & 0.0001 \\
\hline & & Diabetic+Supplement & $12.57 *$ & 2.83 & 0.001 \\
\hline & & Diabetic+Supplement+Training & $27.22 *$ & 2.83 & 0.0001 \\
\hline & \multirow{2}{*}{ Diabetic+Training } & Diabetic+Supplement & -8.77 & 2.83 & 0.04 \\
\hline & & Diabetic+Supplement+Training & 5.87 & 2.83 & 0.36 \\
\hline & Diabetic+Supplement & Diabetic+Supplement+Training & $14.65^{*}$ & 2.83 & 0.0001 \\
\hline \multirow{10}{*}{ TG } & \multirow{4}{*}{ Control } & Diabetic & $-14.17 *$ & 2.66 & 0.001 \\
\hline & & Diabetic+Training & 7.83 & 2.66 & 0.05 \\
\hline & & Diabetic+Supplement & -2.49 & 2.66 & 0.98 \\
\hline & & Diabetic+Supplement+Training & $15.05^{*}$ & 2.66 & 0.0001 \\
\hline & \multirow{3}{*}{ Diabetic } & Diabetic+Training & $22.01 *$ & 2.66 & 0.0001 \\
\hline & & Diabetic+Supplement & $11.68^{*}$ & 2.66 & 0.001 \\
\hline & & Diabetic+Supplement+Training & $29.22 *$ & 2.66 & 0.0001 \\
\hline & \multirow{2}{*}{ Diabetic+Training } & Diabetic+Supplement & $-10.33 *$ & 2.66 & 0.005 \\
\hline & & Diabetic+Supplement+Training & 7.21 & 2.66 & 0.10 \\
\hline & Diabetic+Supplement & Diabetic+Supplement+Training & $17.54 *$ & 2.66 & 0.0001 \\
\hline \multirow{10}{*}{ LDL } & \multirow{4}{*}{ Control } & Diabetic & $-14.65 *$ & 1.87 & 0.0001 \\
\hline & & Diabetic+Training & $6.21 *$ & 1.87 & 0.02 \\
\hline & & Diabetic+Supplement & 4.17 & 1.87 & 0.26 \\
\hline & & Diabetic+Supplement+Training & $17.63 *$ & 1.87 & 0.0001 \\
\hline & \multirow{3}{*}{ Diabetic } & Diabetic+Training & $20.87 *$ & 1.87 & 0.0001 \\
\hline & & Diabetic+Supplement & $18.83^{*}$ & 1.87 & 0.0001 \\
\hline & & Diabetic+Supplement+Training & $32.28^{*}$ & 1.87 & 0.0001 \\
\hline & \multirow{2}{*}{ Diabetic+Training } & Diabetic+Supplement & $-2.03 *$ & 1.87 & 0.95 \\
\hline & & Diabetic+Supplement+Training & $11.41^{*}$ & 1.87 & 0.0001 \\
\hline & Diabetic+Supplement & Diabetic+Supplement+Training & $13.45^{*}$ & 1.87 & 0.0001 \\
\hline \multirow{7}{*}{ HDL } & \multirow{4}{*}{ Control } & Diabetic & $7.73 *$ & 2.19 & 0.01 \\
\hline & & Diabetic+Training & -2.99 & 2.19 & 0.83 \\
\hline & & Diabetic+Supplement & 0.65 & 2.19 & 1 \\
\hline & & Diabetic+Supplement+Training & $-9.05 *$ & 2.19 & 0.003 \\
\hline & \multirow{3}{*}{ Diabetic } & Diabetic+Training & $-10.72 *$ & 2.19 & 0.0001 \\
\hline & & Diabetic+Supplement & $-7.07 *$ & 2.19 & 0.02 \\
\hline & & Diabetic+Supplement+Training & $-16.78 *$ & 2.19 & 0.0001 \\
\hline
\end{tabular}




\begin{tabular}{|c|c|c|c|c|c|}
\hline & Group & Group & Mean Difference & Std. Error & Sig. \\
\hline & Diphtios Twoining & Diabetic+Supplement & 3.65 & 2.19 & 0.64 \\
\hline & Diabetic+ Iraining & Diabetic+Supplement+Training & -6.05 & 2.19 & 0.08 \\
\hline & Diabetic+Supplement & Diabetic+Supplement+Training & $-9.71 *$ & 2.19 & 0.001 \\
\hline \multirow{10}{*}{ Hemoglobin A1C } & \multirow{4}{*}{ Control } & Diabetic & -0.14 & 0.06 & 0.37 \\
\hline & & Diabetic+Training & $1.31 *$ & 0.06 & 0.0001 \\
\hline & & Diabetic+Supplement & 1.03 & 0.06 & 0.0001 \\
\hline & & Diabetic+Supplement+Training & $2.40 *$ & 0.06 & 0.0001 \\
\hline & \multirow{2}{*}{ Diabetic } & Diabetic+Training & $1.45^{*}$ & 0.06 & 0.0001 \\
\hline & & Diabetic+Supplement & $1.17 *$ & 0.06 & 0.0001 \\
\hline & Diabetic & Diabetic+Supplement+Training & $2.54 *$ & 0.06 & 0.0001 \\
\hline & \multirow{2}{*}{ Diabetic+Training } & Diabetic+Supplement & $-0.27 *$ & 0.06 & 0.004 \\
\hline & & Diabetic+Supplement+Training & $1.09 *$ & 0.06 & 0.0001 \\
\hline & Diabetic+Supplement & Diabetic+Supplement+Training & $1.36 *$ & 0.06 & 0.0001 \\
\hline \multirow{10}{*}{ HOMA-IR index } & \multirow{4}{*}{ Control } & Diabetic & $-5.72 *$ & 0.06 & 0.0001 \\
\hline & & Diabetic+Training & $-3.87 *$ & 0.06 & 0.0001 \\
\hline & & Diabetic+Supplement & $-3.70 *$ & 0.06 & 0.0001 \\
\hline & & Diabetic+Supplement+Training & $-3.33^{*}$ & 0.06 & 0.0001 \\
\hline & \multirow{3}{*}{ Diabetic } & Diabetic+Training & $1.85^{*}$ & 0.06 & 0.0001 \\
\hline & & Diabetic+Supplement & $2.02 *$ & 0.06 & 0.0001 \\
\hline & & Diabetic+Supplement+Training & $2.39 *$ & 0.06 & 0.0001 \\
\hline & \multirow{2}{*}{ Diabetic+Training } & Diabetic+Supplement & 0.17 & 0.06 & 0.11 \\
\hline & & Diabetic+Supplement+Training & $0.54 *$ & 0.06 & 0.0001 \\
\hline & Diabetic+Supplement & Diabetic+Supplement+Training & $0.36^{* *}$ & 0.06 & 0.0001 \\
\hline
\end{tabular}

* The mean difference is significant at the 0.05 level.

\section{Discussion}

In this study, the level of fasting blood glucose in 3 groups of diabetic+training group, diabetic, diabetic+Nigella supplement, and diabetic+Nigella supplement+aerobic training group were significantly $(P<0.005)$ lower than that of the beginning of the study. One of the remarkable results of sports activities that confirms the beneficial effects of training for type 2 diabetic patients is the improvement of fasting blood glucose, which showed a significant decrease of $27.39 \%$ in the diabetic+aerobic training group and $40.34 \%$ in the diabetic+Nigella supplement+aerobic training group in the present study. The effect of training on blood glucose requires stimulating the transfer of GLUT-4 transducers from their storage positions within the cell to the membrane of the cell, which is different from that of the insulin-dependent positions. The mechanism of the effect of training involves a different messenger pathway, which can be due to an increase in calcium concentration that is rooted in the activation of the nerve by its neuron, or due to a change in cell energy (i.e., ADP to ATP), which is rooted in the increase in ATP consumption by ATPase enzymes or RONS production (20). Interestingly, the effects of insulin and sports activities have a progressive aspect that supports the fact that their messaging routes are different. On another note, the proposed mechanism for the effect of Nigella supplement consumption on the reduction of blood glucose can be attributed to the flavonoids effect. One of these flavonoids is Mirstin, which effect lipogenesis and glucose transfer from the membrane of adipose tissue cells in the culture medium. Mirstin probably has its own effect on stimulating the absorption of glucose through the fluidity of the membrane lipid layer or the change in the performance of the carriage of glucose, and thus has a therapeutic effect in diabetic patients, and in that the decrease of blood glucose and weight loss can be attributed to the flavonoids in Nigella $(20,21)$. Among the studies that were consistent with the results of the present study, one can point out to Hucker and Bhatt's researches about glucose changes in 2007 and 2011 respectively. The research indicated that the administration of Nigella supplements reduce blood glucose via several mechanisms including insulin sensitivity, intestinal amylase inhibition, inhibition of electro-genic intestinal glucose adsorption, (Advanced Glycation End-18AGE Products), activation of AMPactivated AMPK protein kinase pathway, and increase the 
expression of Glucose transporter 4 (GLUT4) of muscle through increase phosphorylation of Acetylcobarboxylase (22, 23). A research by Hosseini,Nemati,Ranjbar showed that 4 weeks of resistance training resulted in improved glycemic indexes (significant decrease in fasting glucose, insulin and insulin resistance) in streptozoticin-induced diabetic rats, which is consistent with the results of this research (24). Rahimi,Mousavi,Rahimi et al. reported that 12 weeks of aerobic exercise, 3 times a week at $60-65 \%$ at a maximum heart rate did not affect fasting blood glucose. This is inconsistent with the results of this study (25).

According to this study's findings on blood lipids, total cholesterol, triglyceride and LDL index in the diabetic+aerobic training group and diabetic + Nigella supplement+aerobic training group, had the most significant decrease level $(P<0.005)$. Also, in the HDL index, the diabetic+aerobic training group and the diabetic+ Nigella supplement+aerobic training group had the most significant increase $(P<0.005)$. Several studies have been conducted on the response of physical activity to improve lipoproteinemia and to increase HDL concentration along with a decrease in LDL, triglyceride and the beneficial role of physical activity has been shown to increase LDL resistance to the oxidizing process. An increase in LDL-c concentration and a more reduction in HDL-c in this group of patients is one of the risk factors for diabetic patients with cardiovascular disorders (24). Despite the mentioned studies, 4 weeks of resistance training had no effect on improvement of lipid profile in diabetic rats. This inconsistency could be due to the shorter duration of exercise and the type of exercise (26). LDL-c is more likely to accumulate in the blood vessel wall, causing cardiovascular events, while HDL-c causes cholesterol transfers from blood vessels to the liver and prevents lipid accumulation in blood vessels (27). The mechanism by which training improves fat metabolism can be due to changes in the activity of lipase enzymes such as lipoprotein lipase (LPL) and hormone-sensitive lipase (HL). Lipolysis of triglycerides in the adipose tissue are stimulated by phosphorylation and activation of the hormone-sensitive lipase (HSL) with a cascading of cellular signals. As soon as phosphorylation occurs, HSL moves from the cytosol of the adipose cells to the surface of the lipid drops within the cell (28). Prior to HSL's ability to begin to produce lipolysis in the fat drop, perilipins, the proteins present in the fat droplet level, may need to be phosphorylated. Non-phospholipid perilipins prevent lipolysis by creating a barrier between HSL and cell lipid (28). The phosphorylated perilipins may provide access to intracellular triglycerides for HSL by changing the level of fat droplets (28). The results are consistent with the research by Kalim (2006) and Al-Naeeb (2011).
In his study, Kalim (2006) observed that oral administration of Nigella supplements to diabetic rats significantly decreased plasma lipid levels, and in AlNaeeb's (2011) study, it was shown that the consumption of Nigella supplements after eight weeks in hyperlipidemia rabbits significantly reduced levels of triglyceride, cholesterol, and LDL, and increased HDL compared to the control group $(29,30)$. The mechanism of the effect of Nigella supplements on lipid profiles is probably due to the influence of hypolipidemic flavonoids. Flavonoids appear to increase the hypolipidemic activity by increasing LDL-c receptors in the liver, as well as binding to apolipoprotein $\mathrm{B}$, which thereby increases the ability of the liver to perform eradication of LDL-C from the blood (20). Also, the research results of Elmer (2013) were not consistent with the findings of the present study. The researcher showed that 8 weeks of training with an intensity of $80-70 \%$ of maximum oxygen consumption had no significant effect on the lipid profile of young men, which can be the reason for the difference in the type of training, the intensity of the training, as well as the type of subject.

According to the findings of the present study, lipid profiles were observed in the hemoglobin A1C index in the diabetic+ Nigella supplement+aerobic training group, which was the least significant in comparison to other groups $(P<0.005)$. In the insulin index of the control group and the diabetic+ Nigella Supplement+aerobic training group had the highest amount and in the insulin resistance in the training groups is less than the diabetic group. Group changes were statistically significant $(P$ $<0.005)$. Physical activities increase the amount of GLUT4 (plasma membrane glucose transporter) in the trained muscle, which improves insulin function on glucose metabolism and can reduce HbAlc levels (31). A complete body of sport training data has been approved as a way of controlling weight and glycemic control associated with the reduction of HbA1c (32). Improvements in levels of glycosylated hemoglobin and lipid profiles are due to aerobic sport trainings, as well as decreases in inflammatory markers secreted from adipose tissue and given that these inflammatory markers induce insulin resistance, decreased glycosylated hemoglobin and Lipid profile in associated with a decrease in insulin resistance. On the one hand, in the research of Jorgea et al., there was no significant change in $\mathrm{HbA} 1 \mathrm{c}$ levels after aerobic sport training on type 2 diabetic subjects, and on the other hand, Kadogl, Perrea, Lliadis, Angelopoulou, Liapis, Alevioz et al. and Maiorana Reported a significant reduction in $\mathrm{HbA1c}$ after aerobic training $(12,33,34)$. The results are consistent with Maurier, Gautier, Kerviler, Bigard, Villette, Garnier JP. (2007). in their study worked on effects of training on hemoglobin-glycolysis in 
diabetic patients and observed that training was associated with a decrease in hemoglobin glycosylated levels in diabetic patients $(35,36)$. The mechanism of the Nigella supplement effect and training on hemoglobin glycolysis is due to muscle contractions that is insulin-like and sends a large amount of glucose into the cell to produce energy. The possible muscle contraction increases the permeability of the membrane to glucose due to the increase in the balance of glucose carriers in the plasma membrane with training, the increase of the amount of GLUT4 in the trained muscle, which improves the function of insulin on glucose metabolism and can decreases the amount of glycolyzed hemoglobin (37). Dalton and Van Henninin (1985) also reported that no changes in glycolyzed hemoglobin concentrations were observed in non-diabetic patients, which was not consistent with the findings of the present study, with the reason of difference as the method of sport training and the type of subject (38).

\section{Conclusion}

According to the results of this study, it can be concluded that if the Nigella supplement is taken together with aerobic training for 8 weeks, the indices for diabetic patients can be improved, therefore, due to the few number of studies in the usage of Nigella supplements along with aerobic training in different age groups, further research needs to be performed in this field. It is also suggested that in subsequent studies different doses of Nigella supplement should be simultaneously examined in different groups. Also, the use of different aerobic training intensities in longer training term periods can provide more accurate information about the effects of training on these variables. It can also be noted that in experimental and laboratory studies the use of animal models has limitations such as physical characteristics (species, race, age), environmental factors (light, temperature, humidity), food control (supplements, medicine, nutrition), and control of activity (severity, duration, rest), which was made available to the researcher, but factors such as possible physiological changes in the laboratory environment were not controlled.

\section{Acknowledgements}

We would like to thank the efforts of the professors who assisted us throughout this research. This article is part of a PhD thesis at the University of Orumiyeh with the registration number of 1199241.

\section{Conflict of Interest}

Authors declare no conflict of interests.

\section{References}

1. Tofighi A. Babaei S. The effects of separate and combined exercise and nigella supplement on plasmatic levels of apelin and glucose in type 2 diabetes mouse. Urmia Univ Med Sci J. 2016; 27(1): 10-18. [Article]

2. Abou-Seif MA. Youssef AA, Evaluation of some biochemical changes in diabetic patients. Clin Chim Acta. 2004; 346(2): 16170. [DOI:10.1016/j.cccn.2004.03.030] [PMID]

3. Irandoost T, Abdi A, Abbassi Daloii A. Investigating the Effect of 8 Weeks of Aerobic Exercise in Combination with Hydroalcoholic Extract of Cinnamon on Serum Visfatin and Vaspin in Insulin-Resistant Rats. Complement Med J. 2018; 8(1): 2138-52. [Article]

4. Nagi D. Gallen I, ABCD position statement on physical activity and exercise in diabetes. Prac Diabet. 2010; 27(4): 158-63. doi.org/10.1002/pdi.1471 [DOI:10.1002/pdi.1471]

5. Redekop WK, Koopmanschap MA, Stolk RP, Rutten GE, Wolffenbuttel BH, Niessen LW. Health-related quality of life and treatment satisfaction in Dutch patients with type 2 diabetes. Diabetes $\quad$ Care. 2002; 25(3): 458-63. [DOI:10.2337/diacare.25.3.458] [PMID]

6. Antuna-Puente B, Feve B, Fellahi S, Bastard JP. Adipokines: the missing link between insulin resistance and obesity. Diabetes Metab. 2008; 34(1): 2-11. [DOI:10.1016/j.diabet.2007.09.004] [PMID]

7. Ziae-Rad M, Vahdaninia M, Montazeri A. Sexual dysfunctions in patients with diabetes: a study from Iran. Reprod Biol Endocrinol. 2010; 8(1): 50. [DOI:10.1186/1477-7827-8-50] [PMID] [PMCID]

8. Kirwan JP, Solomon TP, Wogta DM, Staten MA, Holloszy Jo. Effects of 7 days of exercise training on insulin sensitivity and responsiveness in type 2 diabetes mellitus. Am J Physiol Endocrinol Metab. 2009; 297(1): E151-6. [DOI:10.1152/ajpendo.00210.2009] [PMID] [PMCID]

9. Umpierre D, Riberio PA, Kramer CK, et al. Physical activity advice only or structured exercise training and association with HbA1c levels in type 2 diabetes: a systematic review and metaanalysis. JAMA. 2011; 305(17): 1790-9. [DOI:10.1001/jama.2011.576] [PMID]

10. Sigal RJ, Kenny GP, Boule NG, et al. Effects of aerobic training, resistance training, or both on glycemic control in type 2 diabetes: a randomized trial. Ann Intern Med. 2007; 147(6): 357 69. [DOI:10.7326/0003-4819-147-6-200709180-00005] [PMID]

11. Goreja WG. Black Seed: Nature's Miracle Remedy. New York, NY: Amazing Herbs Press; 2003.

12. Murugesan T, Kulandaivelu P. Influence of yogic practices and swimming programme on insulin level of diabetic patients. J Bloomers $\quad$ Res. 2011; 3(2): 25-30. [DOI:10.15373/2249555X/FEB2013/102]

13. Ali B, Blunden G. Pharmacological and toxicological properties of Nigella sativa. Phytother Res. 2003; 17(4): 299-305. [DOI:10.1002/ptr.1309] [PMID]

14. Tonoli C, Heyman E, Roelands B, et al. Effects of different types of acute and chronic (training) exercise on glycaemic control in type 1 diabetes mellitus: a meta-analysis. Sports Med. 2012; 42(12): 1059-80. [DOI:10.1007/BF03262312] 
15. Hosseini $\mathrm{S}$, Nikbakht $\mathrm{H}$, Azarbayjani M. The effect of resistance training on glycemic indexes of streptozotocin induced diabetic rats. Physic Educ Sport Sci Quarter. 2011.

16. Adewole SO, Caxton-Martins EA, Ojewole J. Protective Effect of Quercetin on the Morphology of Pancreatic $\beta$-cells of Streptozotocin-Treated Diabetic Rats. Afr J Tradit Complement Altern Med. 2006; 4(1): 64-74. [DOI:10.4314/ajtcam.v4i1.31196] [PMID]

17. Abbasnezhad A, Hayatdavoudi P, Niazmand S, Mahmoudabady M. The effects of hydroalcoholic extract of Nigella sativa seed on oxidative stress in hippocampus of STZ-induced diabetic rats. Avicenna journal of phytomedicine. 2015 Jul;5(4):333. [PMID] [PMCID]

18. American College of Sports Medicine. ACSM's Guidelines for Exercise Testing and Prescription.Philadelphia, PA: Lippincott Williams \& Wilkins; 2013.

19. Gordon NF, Pescatello LS. ACSM's Guidelines for Exercise Testing and Prescription. Philedelphia, PA: Lippincott Williams \& Wilkins; 2009. [DOI:10.1249/FIT.0b013e3181aae1a0]

20. Ghosheh OA, Houdin AA, Crooks PA. High performance liquid chromatographic analysis of the pharmacologically active quinones and related compounds in the oil of the black seed (Nigella sativa L.). J Pharm Biomed Anal. 1999; 19(5): 757-62. [DOI:10.1016/S0731-7085(98)00300-8]

21. Hollman PC, Tijburg LB, Yang CS. Bioavailability of flavonoids from tea. Crit Rev Food Sci Nut. 1997; 37(8): 719-38. [DOI:10.1080/10408399709527799] [PMID]

22. Bhat M, Zinjarde SS, Bhargava SY, Kumar AR, Joshi BN. Antidiabetic Indian plants: a good source of potent amylase inhibitors. Evid Based Complement Alternat Med. 2011; 2011; 810207. [DOI:10.1093/ecam/nen040] [PMID] [PMCID]

23. Houcher Z, Boudiaf K, Benboubetra M, Houcher B. Effects of methanolic extract and commercial oil of Nigella sativa L. on blood glucose and antioxidant capacity in alloxan-induced diabetic rats. Pteridines. 2007; 18(1): 8-18. [DOI:10.1515/pteridines.2007.18.1.8]

24. Hosseini SA, Nemati J, Ranjbar M, Edalatmanesh MA, Zar A. Hypoglycemic Interactive Effects of Ginger Eextract and Eendurance Training in Diabetic Rats. The Horizon of Medical Sciences. 2017; 15; 23(4): 325-30. [Article]

25. Rahimi E, Mousavi nejad ZOS, Rahimi A. Effects of twelve weeks of aerobic training, resistance training or combination of both trainings on the levels of blood sugar, HbAlc and cardiovascular risk factors in women with type 2 diabetes. Int $\mathrm{J}$ App Exercise Physiol. 2014; 3(1): 1-11. [Article]

26. Talebi-Garakani E. The Effect of Resistance Training Intensity on Serum ApoA-I Concentration in Streptozotocin-Induced Diabetic Rats. Iran J Endocrinol Metab. 2013; 15(2): 183-89.
27. Verges B. Lipid modification in type 2 diabetes: the role of LDL and HDL. Fundam Clin Pharmacol. 2009; 23(6): 681-85. [DOI:10.1111/j.1472-8206.2009.00739.x] [PMID]

28. Hargreaves M, Spriet LL. Exercise metabolism. Champaign, IL: Human Kinetics; 2006.

29. Al-Naqeep G, Al-Zubairi AS, Islami M, Amom ZH, Esa NM. Antiatherogenic Potential of Nigella sativa Seeds and Oil in Dietinduced Hypercholesterolemia in Rabbits. Evid Based Complement Alternat Med. 2011; 2011: 213628. [DOI:10.1093/ecam/neq071] [PMID] [PMCID]

30. Kaleem M, Kimani D Asif M, Ahmed Q, Bano B. Biochemical effects of Nigella sativa L seeds in diabetic rats. Indian J Exp Biol. 2006; 44: 745-8.

31. Giannopoulou I, Ploutz Snyder LL, Carhart R, Weinstock RS, Fernhall B, Goulopoulou S, et al. Exercise is required for visceral fat loss in postmenopausal women with type 2 diabetes. J Clin Endocrinol Metab. 2005; 90(3): 1511-18. [DOI:10.1210/jc.2004-1782] [PMID]

32. Motallebi F, Shakerian S, Ranjbar R. Effect of 8 weeks Aerobic Interval Training on Glycosylated Hemoglobin and Insulin Resistance Index in Diabetic Mellitus Type 2 Women. Horizon $\begin{array}{llll}\text { Med Sci. 22(2): } & \text { 137-43. }\end{array}$ [DOI:10.18869/acadpub.hms.22.2.137]

33. Houston ME. Biochemistry primer for exercise science. Champaign, IL: Human Kinetics; 1995.

34. Kadoglou NP, Perrea D, Lliadis F, Angelopoulou N, Liapis C, Alevioz M. Exercise reduces resistin and inflammatory cytokines in patients with type 2 diabetes. Diabetes Care. 2007; 30(3): 719-21. [DOI:10.2337/dc06-1149] [PMID]

35. Mourier A, Gautier JF, De Kerviler E, Bigard AX, Villette JM, Garnier JP et al. Mobilization of visceral adipose tissue related to the improvement in insulin sensitivity in response to physical training in NIDDM: effects of branched-chain amino acid supplements. Diabetes Care. 1997; 20(3): 385-91. [DOI:10.2337/diacare.20.3.385] [PMID]

36. Holloszy J, Constable SH, Young DA. Activation of glucose transport in muscle by exercise. Diabet Metab Res Rev. 1986; 1(4): 409-23. [DOI:10.1002/dmr.5610010405]

37. Karstoft K, Winding K, Knudsen SH, James NG, Scheel MM, Olesen $\mathrm{J}$, et al. Mechanisms behind the superior effects of interval vs continuous training on glycaemic control in individuals with type 2 diabetes: a randomised controlled trial. Diabetologia. $\quad 2014 ; \quad$ 57(10): 2081-93. [DOI:10.1007/s00125-014-3334-5] [PMID]

38. Van Heyningen C, Dalton RG. Glycosylated haemoglobin in iron-deficiency anaemia. The Lancet. 1985; 325(8433): 874. [DOI:10.1016/S0140-6736(85)92234-2] [PMID]

\title{
How to Cite This Article:
}

Babaei bonab S, tofighi A. Effect of 8 weeks Aerobic Training and Nigella Supplement on Insulin Resistance, Lipid Profile and Plasma Level of HbA1c in Type 2 Diabetic Rats. J Adv Med Biomed Res. 2019; 27 (120) :20-29

Download citation:

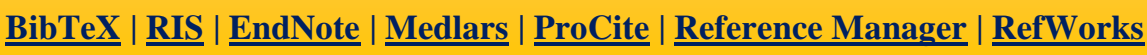

\author{
Send citation to: \\ Mendeley $2 \underline{\text { Zotero }}$ (-) RefWorks $\underline{\text { RefWorks }}$
}

